\title{
Effects of vigabatrin on partial seizures and cognitive function
}

\author{
R A Grünewald, P J Thompson, R Corcoran, Z Corden, G D Jackson, J S Duncan
}

\begin{abstract}
Forty five patients with refractory partial seizures were studied in a prospective, randomised, placebo controlled, add on, parallel group, double blind trial of the new antiepileptic drug vigabatrin $(1.5 \mathrm{~g}$ twice daily) followed by open treatment. Seizure frequency was monitored throughout an eight week baseline, 20 weeks double blind, and up to 18 months of open vigabatrin treatment. Cognitive function, including measures of memory and concentration, mood, and behaviour were assessed at baseline and again during the 20th week of treatment. Vigabatrin was associated with a significant reduction in a measure of motor speed and overall score on a design learning test in the first 20 weeks of treatment. In comparison with the baseline period, vigabatrin treatment was associated with a significant reduction in median complex partial seizure frequency four to 12 and 12 to 20 weeks after commencing vigabatrin $(-66 \%$ and $-69 \%$ in the vigabatrin group, $+50 \%$ and $+25 \%$ in the placebo group). Ten of 20 patients on vigabatrin and four of 23 on placebo showed a $>50 \%$ reduction in complex partial seizure frequency in the last eight weeks of double blind treatment. At least $60 \%$ of responders had maintained the response to vigabatrin when assessed during the open phase of the trial at 44 weeks. Two patients discontinued vigabatrin because of depression, which resolved on drug withdrawal.
\end{abstract}

(F Neurol Neurosurg Psychiatry 1994;57:1057-1063)

Vigabatrin (Sabril, 4-amino-hex-5-enoic acid) is an analogue of $\gamma$-aminobutyric acid (GABA) and selectively inhibits GABA transaminase, ${ }^{1}$ the enzyme responsible for GABA breakdown in the brain. Efficacy against partial seizures has been reported. ${ }^{2-11}$ Although less may be effective, most studies have used doses of $3 \mathrm{~g}$ per day, and an increment in dose from $2 \mathrm{~g}$ to $3 \mathrm{~g}$ per day improves seizure control in about $25 \%$ of patients. ${ }^{2}$ The current study was designed to assess the effects of vigabatrin on memory, cognition, motor speed, and seizures, and is the first report of a prospective, add on, parallel group, double blind, placebo controlled study designed to consider all of these issues.

Vigabatrin has commonly been reported to induce mild and transient side effects including drowsiness, fatigue, dizziness, headache, memory impairment, and diplopia..$^{2-4}$ Depression has been reported in $4-9 \%$ of patients, ${ }^{12}$ and occasionally treatment can be associated with psychotic reactions. ${ }^{13-16}$ Previous studies to investigate cognitive function and mood in patients treated with vigabatrin have shown no deterioration, ${ }^{18}$ or improvement only of response time in an arithmetic task, ${ }^{19}$ but none has used a double blind protocol. Several groups have reported changes in subjectively assessed aggression, irritability, and other mood components, ${ }^{32021}$ but other studies have shown no effect of vigabatrin on mood 1819 and an overall improvement in quality of life and subjective wellbeing as assessed by questionnaire. ${ }^{1821-23}$

\section{Methods}

PATIENTS AND PROCEDURES

Forty five outpatients with partial seizures refractory to optimal antiepileptic drug treatment were studied. Patients had shown an ability to keep an accurate seizure diary distinguishing between simple partial seizures, complex partial seizures, and secondary generalised seizures. On entry into the trial, patients were assessed with a battery of neuropsychological tests to measure general intellectual ability ${ }^{24}$ and linguistic competence, and to familiarise the subjects with the testing procedure. MRI was also performed on all patients. Further psychological assessment took place at the end of an eight week baseline period, and included tests of memory, mental and motor speed, and cognitive flexibility. Patients were then allocated 20 weeks of additional treatment either with vigabatrin ( $1 \mathrm{~g}$ twice daily increasing after 14 days to $1.5 \mathrm{~g}$ twice daily) or with placebo, using a random number generated code and double blind protocol. Patients were clinically assessed every four weeks thereafter, and underwent repeat psychological testing during the last week of the double blind period. Trough serum concentrations of antiepileptic drugs were measured at least once during the baseline and once during the double blind phase of the study. Concomitant medication was maintained constant unless there was clinical evidence of toxicity. After the double blind period all subjects were offered open treatment with vigabatrin ( $1.5 \mathrm{~g}$ twice daily) without breaking the blind, and assessment was continued until treatment modification was required. Patients who had received 
vigabatrin in the double blind period continued on $1.5 \mathrm{~g}$ twice daily; those who had received placebo in the double blind period received $1 \mathrm{~g}$ vigabatrin twice daily and a matching placebo tablet for two weeks, and then received $1.5 \mathrm{~g}$ vigabatrin twice daily. Sixteen of the 22 patients who were allocated vigabatrin at the beginning of the double blind period who had not undergone surgery underwent further neuropsychological assessment between 44 and 68 weeks from the start of the study, as did 18 of the 23 originally allocated placebo.

The numbers of simple partial seizures, complex partial seizures, and secondary generalised seizures were recorded prospectively in seizure diaries during the eight week baseline period and for the eight week periods between four and 12 and 12 and 20 weeks of vigabatrin or placebo treatment. For those allocated treatment with active drug, seizure frequency and type were also analysed in the open phase between weeks 20 and 32 and between weeks 32 and 44 after initiation of vigabatrin treatment.

The study was approved by the ethics committee of the National Hospitals for Neurology and Neurosurgery and all patients gave informed consent.

PSYCHOLOGICAL TESTING

A series of neuropsychological tests was given to determine the effects of vigabatrin on cognitive functioning, including memory, mental speed, mental flexibility, and motor performance. Rating scales of mood and behaviour were also employed. Appointment times were individualised and each patient's assessments were performed at about the same time in the morning. Patients were not prescribed psychotropic medication during the study and did not drink alcohol for 24 hours before the test sessions.

\section{DESCRIPTION OF TESTS}

Memory

Digit span-The digit span subtest from the WAIS-R was employed to assess short term working memory and concentration. ${ }^{24}$ Scores recorded were the maximum number of digits forwards and backwards, and the total number of digits (forwards plus backwards), repeated correctly.

Verbal learning-The list learning test from the adult memory and information processing battery (AMIPB) ${ }^{25}$ was used as a multicomponent measure of verbal learning, including immediate and delayed verbal recall. The test consisted of a list of 15 words that was read to the subject five times (list A). Recall was tested after each presentation (trials 1 to 5) and again after the presentation of a 15 item distracting list (trial 6). The scores recorded were the total number of items recalled over five trials, the number of words recalled after the distracting list, an error score, and the total number of items recalled from the second list (list B).

Verbal recall-The subject was required to recall, both immediately and after a delay of
30 minutes, the main contents of a short paragraph read aloud by the assessor. ${ }^{25}$ The number of items recalled in the immediate and delayed condition and the percentage of information retained from the immediate to the delayed recall test was recorded.

Design learning - This was a non-verbal analogue of the list learning task. ${ }^{25}$ The subject was required to draw from memory a simple geometric design presented for 10 seconds (design A). The design was presented on five occasions and recall tested after each presentation. Recall was tested again after the presentation of a second distracting design. Scores consisted of the total number of design segments correctly reproduced in all five trials (trials 1-5), the number reproduced after the distractor (trial 6), and the number of correct segments recalled from the second design (design $\mathrm{B}$ ).

\section{Mental speed and flexibility}

Information processing speed-The information processing tasks $\mathrm{A}$ and $\mathrm{B}$ from the AMIPB were employed as measures of mental speed..$^{25}$ These tasks involved rapid repetitive mental activity and placed little load on memory, reasoning, or visual perception. In task $A$ the subject was presented with a series of five two digit numbers and was required to strike off the second lowest of the five numbers. The number of correct responses and errors after two minutes on the task were recorded. Task B consisted of a sheet of items comprising a four digit number, a hyphen, and a five digit number. The subject had to cancel the new digit in each item. The number of items correctly cancelled and errors made in two minutes were recorded.

Cognitive flexibility-A modified version of the Stroop test was used to assess mental flexibility. A page was presented on which colour names (for example, red, green, blue) were printed in different coloured inks that were usually incongruous with the colour name. The subject was asked to read through the colour names as quickly as possible. The subject was then instructed to ignore the colour names and to give the colour of the ink in which the words were printed. The time taken and errors made were recorded for the two tasks. A measure of interference was derived by subtracting performance on the experimental task from that of the baseline task.

Fluency-The subject was asked to say as many words as possible beginning with the letter D within sixty seconds. Subjects were then asked to name as many different animals as possible in the same time. The score recorded was the number of novel words produced for each task.

\section{Motor}

Bilateral hand movements-The subject was asked to alternate between a flat hand and a fist as many times as possible in 20 seconds. ${ }^{26}$ The number of successful alternations was recorded.

Tapping rate-This task assessed speed of hand movements between two steel plates, 
with a metal stylus connected to an electronic counter. The subject first undertook the task with the dominant and then with the nondominant hand. For each hand a 15 second practice run was followed by three 15 second trials. The score was the mean of the three trials.

\section{Mood and behaviour \\ Mood adjective checklist-A checklist adapted by Lishman was employed. ${ }^{27}$ The measure consisted of 24 adjectives descriptive of mood states to be rated by the subject on a four point intensity scale. The scores for eight adjectives were combined to give a rating for depression and the scores for four adjectives were summed to give ratings of anxiety, fatigue, activity, and aggression respectively. Hospital anxiety and depression scale-This scale incorporated 14 statements each with four responses representing intensity. ${ }^{28}$ Seven statements referred to feelings associated with anxiety and seven with depression. The sub- ject was asked to respond according to how they had felt over the past few weeks. \\ Behaviour checklist-A behaviour adjective checklist based on the scale devised by Brooks and $\mathrm{McKinley}^{29}$ was completed by a family member. The scale comprised 18 items to be rated on a five point scale, the behavioural end points being specified in each case. A numerical value was assigned to each item and the 18 scores were totalled, a low score indicating more appropriate behaviour.}

STATISTICAL ANALYSIS

Seizure scores for each eight week period were normalised by logarithmic transformation and normality was confirmed by data inspection, and Shapiro Wilks' and Lilliefors' tests. ${ }^{30}$ Repeated measures analysis of variance ${ }^{30,31}$ was performed on serum antiepileptic drug concentrations and logarithmically transformed seizure data, with the statistical package for the social sciences on a Macintosh IIsi computer.

For part of the analysis of seizure and psychological data, subjects were categorised as "responders" if their complex partial seizure frequency decreased by more than $50 \%$.

Baseline variables such as WAIS-R quotients and subject age were analysed by
Student's $t$ test or Wilcoxon signed rank test. Neuropsychological tests repeated as part of the double blind study were analysed by repeated measures analysis of variance. ${ }^{3031}$ Mood adjective checklist scores were compared by the Mann-Whitney test on the difference in scores between first and second assessments. Factors possibly predictive of a response to vigabatrin were analysed with the Wilcoxon signed rank test (continuous variables) or $\chi^{2}$ test (categorical variables).

\section{Results}

Twenty one women and 24 men were studied, with age range 15 to 61 years. Thirty five patients had simple partial seizures, 44 complex partial seizures, and 14 secondary generalised seizures. Thirty four had a clinical and EEG diagnosis of temporal lobe epilepsy, seven of frontal lobe epilepsy and in four the seizure origin was undetermined. Eleven had MRI evidence of left and nine of right hippocampal sclerosis, seven had focal areas of altered signal compatible with gliosis and two discrete foreign tissue lesions. On study entry, 26 patients were receiving monotherapy: 19 with carbamazepine, three with sodium valproate, two with phenytoin, and two with phenobarbitone. Eighteen were taking two and one three antiepileptic drugs.

Twenty two patients were allocated vigabatrin treatment, and 23 placebo. Minor modifications of concomitant antiepileptic drug regimens occurred in two patients in the vigabatrin treated group (one increased phenytoin from $375 \mathrm{mg}$ to $400 \mathrm{mg}$ daily and one decreased carbamazepine from 1400 to 1200 mg daily) and two in the control group (one increased carbamazepine from 1400 to 1600 mg daily and one decreased carbamazepine from 1600 to $1200 \mathrm{mg}$ daily). Patient age and age at onset of seizures were similar in each group (table 1). Of the 22 allocated vigabatrin treatment, 13 underwent further neuropsychological assessment between 44 and 68 weeks from the beginning of the study.

\section{SEIZURE CONTROL}

There was no difference between vigabatrin and placebo treated groups in duration of epilepsy or seizure frequency at baseline

Table 1 Baseline population data and trough serum antiepileptic drug concentrations

\begin{tabular}{|c|c|c|c|c|c|c|}
\hline & \multicolumn{3}{|c|}{$\begin{array}{l}\text { Placebo group (median (range) age } 27(16-55) y \text {; } \\
\text { age at onset } 10(1-22) y)\end{array}$} & \multicolumn{3}{|c|}{$\begin{array}{l}\text { Vigabatrin group (median (range) age 29(17-59)y; } \\
\text { age at onset } 11(2-34) y)\end{array}$} \\
\hline & $\begin{array}{l}\text { Dose (mg) } \\
\text { Median (range) }\end{array}$ & Patients (n) & $\begin{array}{l}\text { Plasma concentration } \\
(\text { mean }(S D)) \\
(\mu \text { molll) }\end{array}$ & $\begin{array}{l}\text { Dose (mg) } \\
\text { Median (range) }\end{array}$ & Patients (n) & $\begin{array}{l}\text { Plasma concentration } \\
(\text { mean }(S D)) \\
(\mu \text { molll) })\end{array}$ \\
\hline \multicolumn{7}{|l|}{ Baseline: } \\
\hline Carbamazepine & $1400(600-2400)$ & 17 & $44(8 \cdot 0)$ & $1200(800-2400)$ & 16 & $42(10)$ \\
\hline Valproate & 2000 & 1 & 880 & $1000(500-2000)$ & 3 & $530(230)$ \\
\hline Phenytoin & $400(300-425)$ & 3 & $66(30)$ & $350(300-500)$ & 6 & $58(29)$ \\
\hline Phenobarbitone & $30(30-150)$ & 2 & $65(85)$ & 120 & 1 & 110 \\
\hline Primidone & $250(250-2250)$ & 2 & $95(87)$ & 1250 & 1 & 51 \\
\hline \multicolumn{7}{|l|}{$\begin{array}{l}\text { Double blind } \\
\text { period: }\end{array}$} \\
\hline Carbamazepine & $1200(800-2400)$ & 13 & $46(7 \cdot 3)$ & $1200(800-2400)$ & 12 & $45(9)$ \\
\hline Valproate & 2000 & 1 & & $1000(500-2000)$ & 3 & $390(360)$ \\
\hline Phenytoin & $375(300-500)$ & 2 & $83(41)$ & $350(300-500)$ & 6 & $52(18)$ \\
\hline Phenobarbitone & $120(30-200)$ & 2 & $120(11)$ & 120 & 1 & 91 \\
\hline Primidone & $1250(125-2250)$ & 2 & $71(72)$ & 1250 & $i$ & 69 \\
\hline
\end{tabular}

Six patients were taking clobazam throughout the trial period, three in the placebo and three in the vigabatrin group. 
Table 2 Seizure frequency at baseline and during double blind treatment

\begin{tabular}{|c|c|c|c|c|c|c|c|c|c|}
\hline & \multicolumn{3}{|c|}{ Baseline } & \multicolumn{3}{|c|}{ Weeks 4-12 } & \multicolumn{3}{|c|}{ Weeks 12-20 } \\
\hline & $S P S$ & CPS & $S G S$ & SPS & CPS & $S G S$ & SPS & CPS & $S G S$ \\
\hline \multicolumn{10}{|l|}{ Placebo group: } \\
\hline Median & 2 & 8 & 0 & 2 & 12 & 0 & 0 & 10 & 0 \\
\hline $\begin{array}{l}\text { Back } \\
\text { transformed }\end{array}$ & $4 \cdot 37$ & $8 \cdot 55$ & 0.58 & $2 \cdot 89$ & $9 \cdot 96$ & 0.32 & $2 \cdot 55$ & $9 \cdot 72$ & 0.48 \\
\hline $\begin{array}{l}\text { mean } \\
\text { Range }\end{array}$ & 55 & 124 & 13 & 178 & 108 & 7 & 249 & 111 & 3 \\
\hline \multicolumn{10}{|l|}{ Vigabatrin group: } \\
\hline Median & 4 & 15 & 0 & $2 \cdot 5$ & 5 & 0 & 4 & 5 & 0 \\
\hline $\begin{array}{l}\text { Back } \\
\text { transformed }\end{array}$ & $5 \cdot 46$ & $9 \cdot 72$ & 0.51 & $3 \cdot 17$ & $4 \cdot 13^{\star}$ & 0.41 & $4 \cdot 62$ & $3 \cdot 57^{\star \star}$ & 0.35 \\
\hline Range & 91 & 38 & 17 & 156 & 26 & 17 & 196 & 47 & 10 \\
\hline
\end{tabular}

$\star \mathrm{p}=0.009 ;{ }^{\star \star} \mathrm{p}=0.001$ (repeated measures analysis of variance, group $\times$ time interaction. Seizure frequency was assessed over eight weeks of baseline treatment. Data include median numbers of each type of seizure recorded during eight week periods (median), antilogarithm of mean of logarithmically transformed seizure data (back transformed mean), and range (minimum number in range is 0 for all categories). SPS = simple partial seizures, CPS = complex partial seizures; SGS = secondary generalised seizures.

evaluation. The back transformed mean seizure frequency in the eight week baseline period was not significantly different in the two groups (table 2). Median frequency of complex partial seizures decreased by $66 \%$ in the vigabatrin treated patients $(1.5 \mathrm{~g}$ twice daily) between four and 12 weeks of treatment, which was significantly better than the control group ( $50 \%$ increase in control group; group $\times$ time interaction $p=0 \cdot 009)$. Between 12 and 20 weeks of vigabatrin treatment the median decrease in complex partial seizure frequency was $69 \%$ (25\% increase in control group; group $\times$ time interaction $\mathrm{p}=0.001$ ). The decrease in frequency of simple partial seizures and secondary generalised seizures seen at both time points was not significantly different from the placebo group (table 2).

More patients in the vigabatrin treatment group improved than in the placebo group. Nine of the 22 patients on vigabatrin had a greater than $50 \%$ decrease in complex partial seizure frequency between weeks 4-12 and 10 between weeks $12-20$ of the double blind treatment period compared with the baseline period; four patients allocated placebo showed this magnitude of reduction in complex partial seizure frequency during weeks 412 (not significant) and three patients during weeks $12-20$ of the double blind period ( $\mathrm{p}=$ 0.016 by Pearson $\chi^{2}$ test).

In comparison with the baseline period, seizure control deteriorated in fewer patients receiving vigabatrin in the double blind treatment period than in those receiving placebo.
One of the 22 patients on vigabatrin showed $>50 \%$ increase in complex partial seizures between weeks 4-12 of the double blind study compared with the baseline period, and none between weeks 12 and 20 . Of the 23 patients allocated placebo, seven had $>50 \%$ more complex partial seizures during weeks 4-12 ( $\mathrm{p}=0.023$ by Pearson $\chi^{2}$ test), and seven during weeks $12-20$ of the study $(\mathrm{p}=0.005$ by Pearson $\chi^{2}$ test).

Forty three patients entered the open phase of the trial, 23 from the placebo group and 20 from the vigabatrin treated group. On entering the open phase of the trial, seven of the 10 responders to vigabatrin continued the drug at $3 \mathrm{~g}$ /day; three withdrew, two to try other drug regimens, one for surgical assessment). When assessed at 44 weeks after commencing vigabatrin, seizure control had continued to improve or improvement was sustained in six of the seven but one patient had deteriorated slightly (table 3 ).

There were no significant pharmacokinetic interactions with concomitant antiepileptic drugs (table 1) and no significant changes in biochemical (serum urea and electrolytes, glucose, bilirubin, liver enzymes, creatinine, and uric acid) or haematological (haemoglobin concentration, red cell volume, and differential white cell and platelet counts) variables.

\section{ADVERSE EFFECTS}

Forty three patients completed the double blind phase of the study. Two patients allocated vigabatrin developed severe depressive

Table 3 Long term seizure frequency in patients responding to vigabatrin

\begin{tabular}{|c|c|c|c|c|c|c|c|c|}
\hline \multirow[b]{2}{*}{ Patient No } & \multicolumn{4}{|c|}{ Complex partial seizures } & \multicolumn{4}{|c|}{ Total seizures } \\
\hline & Baseline & $\begin{array}{l}\text { Weeks } \\
4-12\end{array}$ & $\begin{array}{l}\text { Weeks } \\
12-20\end{array}$ & $\begin{array}{l}\text { Weeks } \\
36-44\end{array}$ & Baseline & $\begin{array}{l}\text { Weeks } \\
4-12\end{array}$ & $\begin{array}{l}\text { Weeks } \\
12-20\end{array}$ & $\begin{array}{l}\text { Weeks } \\
36-44\end{array}$ \\
\hline 4 & 12 & 9 & 5 & Withdrew & 21 & 25 & 30 & Withdrew \\
\hline 7 & 27 & 11 & 8 & 3 & 51 & 24 & 24 & 10 \\
\hline 12 & 15 & 2 & 0 & 0 & 19 & 4 & 1 & 0 \\
\hline 19 & 38 & 18 & 15 & Withdrew & 41 & 18 & 17 & Withdrew \\
\hline 23 & 8 & 4 & 5 & 3 & 8 & 4 & 5 & 3 \\
\hline 25 & 6 & 0 & 0 & 1 & 9 & 0 & 0 & 1 \\
\hline 26 & 3 & 4 & 0 & 0 & 3 & 4 & 0 & 0 \\
\hline 31 & 20 & 5 & 2 & 1 & 20 & 5 & 2 & 3 \\
\hline 34 & 16 & 1 & 1 & Withdrew & 124 & 174 & 207 & Withdrew \\
\hline 39 & 3 & 0 & 0 & 0 & 8 & 4 & 10 & 4 \\
\hline
\end{tabular}

Figures represent seizures recorded during eight week periods in 10 patients who responded to vigabatrin out of the 22 patients who took the drug from the beginning of the double blind phase of the trial. 
Table 4 Neuropsychological data at baseline and week 20 (double blind phase)

\begin{tabular}{|c|c|c|c|c|c|c|c|c|}
\hline \multirow[b]{3}{*}{ Trial } & \multicolumn{4}{|c|}{ Placebo group scores } & \multicolumn{4}{|c|}{ Vigabatrin group scores } \\
\hline & \multirow{2}{*}{$\frac{\text { Baseline }}{\text { Mean }}$} & \multirow[b]{2}{*}{$(S D)$} & \multirow{2}{*}{$\frac{\text { Week } 20}{\text { Mean }}$} & \multirow[b]{2}{*}{$(S D)$} & \multirow{2}{*}{$\frac{\text { Baseline }}{\text { Mean }}$} & \multirow[b]{2}{*}{$(S D)$} & \multicolumn{2}{|l|}{ Week 20} \\
\hline & & & & & & & Mean & $(S D)$ \\
\hline \multicolumn{9}{|l|}{ Memory: } \\
\hline List $A$ trials 1 to $5 \dagger$ & $41 \cdot 7$ & $(8 \cdot 9)$ & $43 \cdot 0$ & $(8 \cdot 0)$ & $44 \cdot 9$ & $(7 \cdot 5)$ & $42 \cdot 9$ & $(9 \cdot 5)$ \\
\hline List $\mathrm{B} \dagger$ & 4.9 & $(2 \cdot 1)$ & $5 \cdot 3$ & $(1.5)$ & $5 \cdot 3$ & $(1 \cdot 4)$ & $4 \cdot 8$ & $(1 \cdot 7)$ \\
\hline Trial $6 \dagger$ & $7 \cdot 4$ & $(3 \cdot 3)$ & $8 \cdot 6$ & $(2 \cdot 3)$ & $8 \cdot 3$ & $(3 \cdot 2)$ & $8 \cdot 3$ & $(2 \cdot 8)$ \\
\hline Immediate story recall $\dagger$ & $14 \cdot 3$ & $(7 \cdot 0)$ & $20 \cdot 7$ & $(9 \cdot 2)$ & $14 \cdot 2$ & $(7 \cdot 4)$ & $19 \cdot 5$ & $(8.9)$ \\
\hline$\%$ retained $\dagger$ & $76 \cdot 8$ & $(29 \cdot 7)$ & $69 \cdot 8$ & $(28 \cdot 7)$ & $73 \cdot 0$ & $(27 \cdot 0)$ & $80 \cdot 3$ & $(26 \cdot 6)$ \\
\hline Design A trials 1 to $5 \dagger$ & $29 \cdot 3$ & $(9 \cdot 2)$ & $33 \cdot 8$ & $(8 \cdot 4)$ & $31 \cdot 4$ & $(11 \cdot 1)$ & $30 \cdot 0$ & $(10 \cdot 0)^{\star}$ \\
\hline Design Bt & $5 \cdot 5$ & $(2 \cdot 3)$ & $4 \cdot 1$ & $(1 \cdot 8)$ & $5 \cdot 2$ & $(2 \cdot 2)$ & $4 \cdot 5$ & $(2 \cdot 6)$ \\
\hline Trial $6 t$ & $6 \cdot 3$ & $(2 \cdot 5)$ & $7 \cdot 5$ & $(2 \cdot 3)$ & $6 \cdot 5$ & $(2 \cdot 7)$ & $6 \cdot 7$ & $(2 \cdot 6)$ \\
\hline \multicolumn{9}{|l|}{ Mental speed and flexibility: } \\
\hline Processing task A time & $31 \cdot 0$ & $(8 \cdot 7)$ & $28 \cdot 5$ & $(9 \cdot 2)$ & $30 \cdot 8$ & $(9 \cdot 2)$ & $27 \cdot 9$ & $(9 \cdot 2)$ \\
\hline Processing task B time $\neq$ & $26 \cdot 3$ & $(9 \cdot 4)$ & $26 \cdot 6$ & $(9 \cdot 0)$ & $25 \cdot 3$ & $(10 \cdot 1)$ & $26 \cdot 2$ & $(7 \cdot 9)$ \\
\hline Stroop colours $\dagger$ & $136 \cdot 8$ & $(58 \cdot 4)$ & $98 \cdot 9$ & $(20 \cdot 3)$ & $159 \cdot 6$ & $(89 \cdot 0)$ & $113 \cdot 1$ & $(31 \cdot 7)$ \\
\hline Fluency (words) $\dagger$ & $10 \cdot 6$ & $(5 \cdot 0)$ & $10 \cdot 5$ & $(5 \cdot 2)$ & $8 \cdot 7$ & $(5 \cdot 6)$ & $9 \cdot 8$ & $(6 \cdot 8)$ \\
\hline Fluency (animals) $\dagger$ & $17 \cdot 1$ & $(4 \cdot 8)$ & $16 \cdot 9$ & $(4 \cdot 0)$ & $16 \cdot 3$ & $(5 \cdot 3)$ & $15 \cdot 5$ & $(5 \cdot 5)$ \\
\hline \multicolumn{9}{|l|}{ Motor speed: } \\
\hline Bilateral hand movements $\dagger$ & $44 \cdot 6$ & $(16 \cdot 3)$ & $42 \cdot 7$ & $(14 \cdot 8)$ & $40 \cdot 0$ & $(12 \cdot 8)$ & $41 \cdot 3$ & $(12 \cdot 1)$ \\
\hline Tapping task (dominant) $\dagger$ & $85 \cdot 6$ & $(14 \cdot 3)$ & $92 \cdot 0$ & $(19 \cdot 1)$ & $77 \cdot 0$ & $(15 \cdot 0)$ & $72 \cdot 1$ & $(14 \cdot 5)^{\star \star}$ \\
\hline Tapping task (non-dominant) $\dagger$ & $74 \cdot 0$ & $(9 \cdot 7)$ & $78 \cdot 2$ & $(12 \cdot 7)$ & $67 \cdot 6$ & $(13 \cdot 8)$ & $67 \cdot 5$ & $(13 \cdot 7)$ \\
\hline
\end{tabular}

For descriptions of neuropsychological tests see text. ${ }^{\star} \mathrm{p}<0.04 ;{ }^{\star \star} \mathrm{p}<0.01$ : significance calculated by repeated measures analysis of variance (drug $\times$ time interaction). + Higher score better performance. $\neq$ Lower score better performance.

symptoms and withdrew within four weeks of starting treatment. In both, symptoms improved within four weeks of vigabatrin withdrawal. Other adverse effects reported by two or more subjects in the trial included weight gain (four of 22 vigabatrin, two of 23 placebo), headache (one of 22 vigabatrin, four of 23 placebo), constipation (five of 22 vigabatrin, one of 23 placebo), fatigue (four of 22 vagabatrin, three of 23 placebo), mild depression (four of 22 vigabatrin, two of 23 placebo), dizziness (three of 22 vigabatrin, one of 23 placebo), double vision (three of 22 vigabatrin, two of 23 placebo), tremor (two of 22 vigabatrin, three of 23 placebo) and impaired memory (two of 22 vigabatrin, 0 of 23 placebo). The only difference that approached statistical significance was constipation ( $p=0.07$, Pearson's $\chi^{2}$ test).

In the open phase of the trial one of the 23 patients who switched from placebo to vigabatrin had to withdraw because of the development of depression within four weeks of commencing vigabatrin. In this patient the symptoms also improved within four weeks of vigabatrin withdrawal.

\section{NEUROPSYCHOLOGICAL ASSESSMENT}

There was no significant difference in IQ (mean (SD) of the placebo group 90.8 (9.8) and of the vigabatrin treated group 92.7 $(14 \cdot 3)$ ) or other neuropsychological test scores between the treatment and placebo groups at baseline.

There were significant improvements in performance over time, unrelated to drug or placebo treatment (practice effects), in scores for Stroop reaction time, digit span, story recall, subtests of design recall, and motor task errors (table 4).

Vigabatrin treatment was associated with a significant reduction in dominant hand tapping frequency (mean baseline tapping rate 85.6 in placebo group, 77.0 in treatment group, rising to 92 at the end of the double blind period in the placebo group but falling to $72 \cdot 1$ in the vigabatrin treated group; group $\times$ time interaction $p=0.01$, table 4 ). The overall score of the design learning task also showed a vigabatrin associated deterioration (mean baseline score 29.3 in placebo group, 31.4 in treatment group, rising to 33.8 in placebo group but falling to 30.3 in the vigabatrin treated group; group $\times$ time interaction $\mathrm{p}=0.04$; table 4 ). Other tests did not show a significant group $\times$ time interaction; in particular, vigabatrin treatment was not associated with any significant change in measures of mood or behaviour in those who tolerated the drug.

Neuropsychological reassessment of 13 of those patients allocated vigabatrin in the double blind phase took place after between 44 and 68 weeks from the beginning of the double blind study. For technical reasons, in only three patients was it possible to reassess the tapping task: mean tapping rate rose from 59 to 70 between 28 and $44-68$ weeks of continuous treatment, whereas in two patients who discontinued vigabatrin it fell from $75 \cdot 7$ to $74(p=0.047$ by repeated measures analysis of variance). There was no evidence of further deterioration of design learning with prolonged vigabatrin treatment in nine patients who were reassessed during the open phase. The mean overall score of the design learning task rose from 28.3 to 37.3 in nine patients who continued vigabatrin, and from 30.6 to 31.4 in four who discontinued the drug (NS).

Within the vigabatrin treated group, tests of memory, mental speed and flexibility, and motor performance did not change differently in those who responded to vigabatrin $>50 \%$ reduction in complex partial seizure frequency) compared with those who did not. Some scores on the mood adjective checklist, however, showed a significant improvement in vigabatrin responders compared with 
Table 5 Mood Adjective checklist scores in patients receiving vigabatrin during the double blind phase of study divided according to response

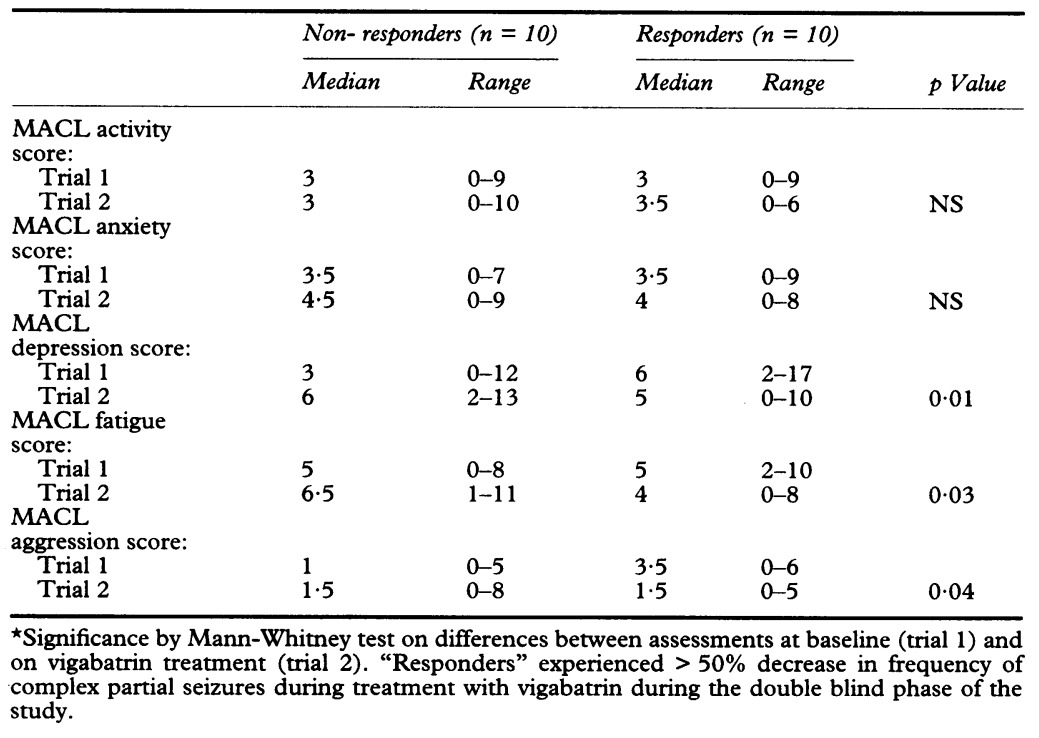

non-responders (depression score $p=0.01$, fatigue score $\mathrm{p}=0.03$, aggression score $\mathrm{p}=$ $0 \cdot 04$, table 5).

\section{FACTORS PREDICTIVE OF RESPONSE TO VIGABATRIN}

The following factors were analysed for potential to predict the therapeutic response to vigabatrin: age, site of epileptic focus, presence of hippocampal sclerosis (defined by MRI), ${ }^{32}$ site of electroencephalographic seizure focus, duration of epilepsy, age of onset of seizures, and history of febrile convulsion. No significant predictive potential was identified for any factor.

\section{Discussion}

Patients recruited for this study had drug resistant partial seizures. Despite this, vigabatrin treatment was effective. There was a > $50 \%$ improvement in the control of complex partial seizures in $45 \%$ of patients during the double blind period of 20 weeks of treatment, and a statistically significant improvement in overall complex partial seizure frequency compared with the placebo control group. The reductions in simple partial seizures and secondary generalised seizure frequencies associated with vigabatrin were not significant. Of those who responded to the drug, at least $60 \%$ continued to respond at 44 weeks. One vigabatrin treated patient became seizure free from 32 to 44 weeks of treatment, and one from 12 to 56 weeks of treatment although at review at 64 weeks this patient had experienced two simple partial seizures. No patient factors predictive of response could be identified; for instance those with well defined focal abnormalities on brain imaging responded as well as those with normal brain imaging.

Although vigabatrin treatment $(1.5 \mathrm{~g}$ twice daily) was generally well tolerated, potentially serious adverse psychiatric effects (depression) occurred in $9 \cdot 1 \%$ (two of 22 ) during the double blind phase and in a further $4.3 \%$ (one of 23) of those introduced to the drug in the open phase of the trial. These developed within four weeks of starting vigabatrin and were rapidly reversible on discontinuation of the drug. These rates are slightly higher than have generally been reported in other studies. ${ }^{2-11}$ In this study vigabatrin was introduced rapidly ( $2 \mathrm{~g} /$ day for two weeks increasing to $3 \mathrm{~g} /$ day), and more gradual introduction of the drug may produce lower rates of intolerance. There were no cases of vigabatrin related psychosis. ${ }^{13-16}$ Scores on the mood adjective checklist, behavioural rating, and hospital anxiety and depression scale indicated that no vigabatrin related adverse effects had been detected by patients or families of those who tolerated the drug.

Of the neuropsychological tests only the dominant hand tapping rate and the overall score of the design learning task showed significant vigabatrin associated impairment. The magnitude of the effect on dominant hand tapping was of the order of $14 \%$; the other motor tasks tested, bilateral hand movements and non-dominant hand tapping, showed no significant change. Unblinded assessment of three patients who were available for further testing after 44 weeks of vigabatrin treatment showed an improvement in motor function compared with two patients who had stopped the drug. This finding is consistent with the development of tolerance to vigabatrin induced motor slowing.

Impairment of motor speed is a recognised adverse effect of antiepileptic drugs. Treatment with phenytoin has been associated with impaired motor performance, ${ }^{33}$ and withdrawal of phenytoin, carbamazepine, and sodium valproate with improvement in motor speed. ${ }^{34}$ Vigabatrin is known to effect motor function, and has been successfully used to treat spasticity due to multiple sclerosis and spinal cord disease. ${ }^{12}$ Further studies are required to confirm that the vigabatrin associated motor impairment is fully reversible on drug withdrawal.

A statistically significant impairment of a measure of visual memory developed in the vigabatrin treated group, although the magnitude of the change was not great. Subjective memory impairment was reported in $9 \%$ (two of 22) patients allocated vigabatrin in the double blind period of this study; this has been previously reported as an adverse effect of vigabatrin treatment. ${ }^{12}$ Objective vigabatrin related memory impairment, however, has not previously been reported. Patients with partial seizures, especially those with temporal lobe epilepsy, may have pre-existing memory dysfunction, ${ }^{35}$ and may therefore be more sensitive to drug induced memory impairment. Although it is not yet possible to determine whether the effect is fully reversible on vigabatrin withdrawal, retesting of the patients who continued the drug between 44 and 52 weeks of treatment showed no evidence of further decline in memory function. The absence of vigabatrin related changes in other neuropsychological test scores implies that the drug did 
not induce major cerebral cognitive impairment after 20 weeks of treatment. As the design learning task was not critically dependent on motor speed, impaired performance in the vigabatrin treated group could not be accounted for by motor slowing.

Analysis of objective neuropsychological test scores according to drug responsiveness in the vigabatrin treated group showed that those patients whose complex partial seizure frequency fell by $>50 \%$ did not differ from the remainder of the group, implying that the patients' performance in these tests was not significantly impaired by seizures. The significant improvements in the subjective mood adjective checklist scores of depression, fatigue, and aggression in vigabatrin responders as compared with non-responders reflect positive mood changes in those whose seizures had improved. This effect may not be drug specific and may be a response to improved seizure control.

In conclusion, vigabatrin treatment was effective in reducing complex partial seizure frequency in a group of patients with refractory partial epilepsy: $45 \%$ had a $>50 \%$ reduction in seizures. In at least $60 \%$ of those who responded to the drug, the therapeutic effect was sustained over the 44 week study period. Nine per cent of patients treated were intolerant of vigabatrin because of depression that reversed on stopping the drug. Vigabatrin treatment was associated with a small but statistically significant reduction in motor speed and a modest impairment of performance on a visual memory task. The influence of long term treatment and reversibility of these effects on withdrawal of vigabatrin remain to be established.

\section{Addendum}

Since this paper was submitted, Gillham et al ${ }^{36}$ have reported 24 patients who received add on treatment with vigabatrin ( $1 \mathrm{~g}$ twice daily for six weeks then $1.5 \mathrm{~g}$ twice daily for six weeks) or placebo in a cross over study. Patients reported sedation when first treated with vigabatrin; there was no evidence of cognitive impairment.

We are grateful to Marion Merrell Dow for supporting this investigation and for the supply of vigabatrin and matching placebo medication.

1 Schechter PJ. Clinical pharmacology of vigabatrin. $\mathrm{Br} \mathcal{F}$ Clin Pharmacol 1989;27(suppl):19S-22S

2 Mumford JP, Dam M. Meta-analysis of European placebo controlled studies of vigabatrin in drug resistant epilepsy. Br 7 Clin Pharmacol 1989;27(suppl):1 19S-24S.

3 Rimmer EM, Richens A. Double-blind study of $\gamma$-vinyl GABA in patients with refractory epilepsy. Lancet 1984;i: 189-190.

4 Pedersen SA, Klosterskov P, Gram L, Dam M. Long-term study of gamma-vinyl GABA in the treatment study of gamma-vinyl GABA in the
epilepsy. Acta Neurol Scand $1985 ; 72: 295-8$.
5 Michelucci $R$, Tassinari A. Response to vigabatrin in relation to seizure type. $\mathrm{Br} \mathcal{F}$ Clin Pharmacol 1989; 27(suppl):125S-9S.

6 Gram L, Klosterskov P, Dam M. $\gamma$-vinyl GABA: a doubleblind placebo-controlled trial in partial epilepsy. Ann Neurol 1985;17:262-6.

7 Browne TR, Mattson RH, Penry JK, et al. Vigabatrin for refractory complex partial seizures: multi-centre singleblind study with long-term follow-up. Neurology 1987; 37:184-9.

8 Ben-Menachem E, Persson L, Mumford J. Long-term evaluation of once daily vigabatrin in drug-resistant partial epilepsy. Epilepsy Research 1990;5:240-6.

9 Cocito L, Maffini M, Perfumo P, et al. Vigabatrin in complex partial seizures: a long-term study. Epilepsy Research 1989;3:160-6.

10 Reynolds EH, Ring HA, Farr IN, et al. Open, double-blind and long-term study of vigabatrin in chronic epilepsy. Epilepsia 1991;32:530-8.

11 Knott C, Panayiotopoulos CP. Vigabatrin in the treatment of complex partial seizures. Seizure 1992;1:167-72.

12 Grant S, Heel RC. Vigabatrin: a review of its pharmacodynamic and pharmacokinetic properties, and therapeutic potential in epilepsy and disorders of motor control. potential in epilepsy and

13 Sander JWAS, Hart YM. Vigabatrin and behaviour disturbances. Lancet 1990;335:57.

14 Betts T, Thomas L, Johnston SJ. Vigabatrin and behaviour disturbances. Lancet 1990;335:606.

15 Ring HA, Reynolds EH. Vigabatrin and behaviour disturbance. Lancet 1990;335:970.

16 Brodie MJ, McKee PJW. Vigabatrin and psychosis. Lancet 1990;335:1279.

17 Kalviainen $R$, Aikia M, Saksa M, et al. Cognitive effects of vigabatrin monotherapy. Acta Neurol Scand 1990; 82(suppl 133): 13

18 Mumford JP, Beaumont D, Gisselbrecht D. Cognitive function, mood and behaviour in vigabatrin treated patients. Acta Neurol Scand 1990;82(suppl 133): 15.

19 McGuire AM, Duncan JS, Trimble MR. Effects of vigabatrin on cognitive function and mood when used as add-on therapy in patients with intractable epilepsy. Epilepsia therapy in patients

20 Loiseau P, Hardenberg JP, Pestre M, et al. Double blind, placebo-controlled study of vigabatrin (gamma-vinyl GABA) in drug-resistant epilepsy. Epilepsia 1986;27: 115-20

21 Matailainen R, Pitkanen A, Ruutiainen T, et al. Effect of vigabatrin on epilepsy in mentally retarded patients: a 7month follow-up study. Neurology 1988;38:743-7.

22 Tartara A, Manni R, Galimberti A, Hardenberg J, Orwin J, Perucca E. Vigabatrin in the treatment of epilepsy: a double-blind, placebo-controlled study. Epilepsia 1986; 27:717-23.

23 Sivenius MR, Ylinen A, Murros $K$, Matailainen R, Riekkinen P. Double blind dose reduction study of vigabatrin in complex partial epilepsy. Epilepsia 1987;28: 688-92.

24 Wechsler D. WAIS-R Manual. New York: Psychological Corporation, 1981

25 Coughlan AK, Hollows SE. The adult memory and information processing battery. Leeds: Psychology Department, 1985

26 Wyke $M$. Influence of direction on the rapidity of bilateral arm movements. Neuropsychologia 1969;7:189-94.

27 Lishman WA. Selective factors in memory: part 2: affective disorder. Psychol Med 1971;2:248-53.

28 Zigmund AS, Snaith RP. The hospital anxiety and depression scale. Acta Psychiatr Scand 1983;67:361-70.

29 Brooks DN, McKinley W. Personality and behavioural change after severe blunt head injury - a relative's view. f Neurol Neurosurg Psychiatry 1983;46:336-44.

30 Norusis MJ. Repeated measures analysis of variance. In: SPSS advanced statistics student guide. Chicago, Ill: SPSS SPSS advanced statistics
Inc, 1990:270-306.

31 Horton RL. The general linear model. New York: McGraw Hill, 1978 .

32 Jackson GD, Berkovic SF, Duncan JS, Connelly A. Optimising the diagnosis of hippocampal sclerosis using magnetic resonance imaging. American fournal of Neuroradiology 1993;114:753-62.

33 Dodrill CB, Temkin NR. Motor speed is a contaminating factor in evaluating the "cognitive" effects of phenytoin. Epilepsia 1989;30:453-7.

34 Duncan JS, Shorvon SD, Trimble MR. Effects of removal of phenytoin, carbamazepine and sodium valproate on cognitive function. Epilepsia 1990;31:584-91.

35 Halgnen E, Stapleton J, Domalski P, et al. Memory dysfunction in epilepsy patients as a derangement of normal physiology. Adv Neurol 1991;55:385-410.

36 Gillham RA, Blacklaw J, McKee PJW, Brodie MJ. Effect of vigabatrin on sedation and cognitive function in patients with refractory epilepsy. $\mathscr{f}$ Neurol Neurosurg patients with refractory
Psychiatry 1993;56:1271-5. 